\title{
Business Intelligence in a Local Government Unit
}

\author{
Małgorzata Nycz \\ Wrocław University of \\ Economics, Wrocław, \\ Poland
}

malgorzata.nycz@ue.wroc.pl

\author{
Zdzisław Pólkowski \\ Lower Silesian University of \\ Entrepreneurship and \\ Technology, Polkowice, Poland
}

z.polkowski@dwspit.pl

\begin{abstract}
Business Intelligence is an important tool to improve business processes. More and more companies, government units use BI. But there are not still so many solutions which can be applied in local government units. For this reason the paper has been devoted to the supporting managerial decision-making processes in the Polkowice commune, Poland using BI technology. It consists of the following parts. After a brief introduction to the matter of local government units, the problem statement, the goal of study, research questions, methodology were presented. The next part has been devoted to short presentation of main tasks of the local government units on the example of the Polkowice Community. Then the role of BI in a local government unit has been shown. In the next part Business Intelligence is recommended as a modern technology supporting management within local government units and it is shown where, which area of their activity should be supported by the BI technology. The conclusion and contribution end the paper.
\end{abstract}

Keywords: information and communications technology, local government units, business intelligence (BI), business processes

\section{Introduction}

The process of obtaining important and high-quality information, which aids managers in analyses, drawing conclusions, or making assumptions, is a process where using OLAP (Online Analytical Processing) technology and data analysis, users are provided sufficient answers to important business questions (Himanshu Tiwari, 2014).

Launching dedicated IT (Information Technology) solutions in local government units is now the foundation of implementing the Strategy for Sustainable Development in Poland (GUS, 2011). By following the idea of the common good, contemporary public institutions focus their attention on restoring order and coherence of activities that are one of the most important factors for a de-

Material published as part of this publication, either on-line or in print, is copyrighted by the Informing Science Institute. Permission to make digital or paper copy of part or all of these works for personal or classroom use is granted without fee provided that the copies are not made or distributed for profit or commercial advantage AND that copies 1) bear this notice in full and 2) give the full citation on the first page. It is permissible to abstract these works so long as credit is given. To copy in all other cases or to republish or to post on a server or to redistribute to lists requires specific permission and payment of a fee. Contact Publisher@InformingScience.org to request redistribution permission. cision-maker of every institution. Attempts to achieve a future comprehensiveness in managing a public institution are determined by currently made investment decisions and modernizations. Acting in the era of knowledge (as well as information) forces organizations to manage this valuable resource in a special way, because the use of knowledge is often key for an organization to be or not to be on the market. As we live in an 
information society, and the economy heads towards being called a knowledge-based economy, the use of intelligent IT systems has become a key to manage an organization (Kamińska, 2010). Efficiency and increasing effectiveness in the functioning of public entities should be among the main goals. In order to meet new market requirements and adapt to trends, local government units aspire to become leaders in the administrative services sector, not only by providing services adjusted to the needs of society but, above all, by implementing new technologies that make it possible to manage the knowledge comprehensively, which makes it possible to manage an institution efficiently (Sauer, 2013).

\section{Problem Statement}

Though numerous studies have cited the business value of BI, there has been little geared towards the context of the public sector and fewer still at a local government or municipal level. BI implementations within the government or public sector do not have as many references in literature; therefore, this paper can be useful in identifying the role BI can play in that context through investigating a Polish local government unit (Olawale, 2012, p. 6).

Although the authors are directly responsible for the computerization and have many contacts with_scientists and directors, BI tools in use in a similar local government unit is unknown to them. Business process management with information systems is possible in the case of local government units, but quite difficult. Moreover, efficient data entry is impossible in many cases.

\section{Goal of the Study}

In recent years, several publications have documented new BI solutions. The goal of modernization- oriented solutions being implemented is to not only achieve positive economic effects for a city, region or country itself. Such activities must prepare it to meet future needs that are generated by the society classified as the information society, with knowledge acting as the key element. The knowledge can be located in various potential resources of local government units. The intellectual capital, which is the sum of the knowledge of the people who create an organization and a value that defines a company's general value different than its financial value, as well as the knowledge from databases gathered in a given institution for years, can be considered as such resources.

Even though the efficiency of BI has been improved in recent years, most improvements mentioned above have been achieved by implementing and testing in business. Also, several studies have indicated while some BI solutions have appeared in government, little attention has been given to the local government units. Nonetheless, it is possible to further improve the current situation. With this goal, this paper explores new fields to implement BI in local government units, based on the example of a social welfare center in Polkowice.

\section{Research Questions}

This paper aims to investigate why and how BI can be used in local government units. The following questions are addressed:

- Why do local government units require BI?

- How can BI play a role in local government units regarding planning and effective utilization of resources? 


\section{Methodology}

When should a case study approach be used? According to Yin (Yin, 2003) a case study design should be considered when: (a) the focus of the study is to answer "how" and "why" questions (b) you cannot manipulate the behavior of those involved in the study (c) you want to cover contextual conditions because you believe they are relevant to the phenomenon under study (d) the boundaries are not clear between the phenomenon and context (Baxter \& Jack, 2008).

This methodology seems appropriate for the explorative objectives of this research, as it aimed to build information and communications technology systems with BI solutions. It has been proven many times that the assumptions presented in the literature of the subject and related to knowledge management are not always translated into business practice. There is a continuous large gap between the theory and reality in which businesses operate. This was also confirmed by research conducted in 2008 (Olszak \& Ziemba, 2010).

The need for implementation of BI mobile and Internet technologies leads to creation of the concept of the model of fully integrated IT system in local government units. The presented concept is mainly influenced by development of new information and communications technology solutions, such as service-oriented architecture, cloud computing, business intelligence and knowledge management (Nycz, Pólkowski, 2014).

In order to present the impact of BI on public administration in Poland, the issue of the role of BI in a local government unit was described. In particular, this question was explored: Why do local government units require Business Intelligence? Next, solutions that can be implemented in Polkowice were analyzed.

\section{Tasks of the Local Government Units on the Example of the Centre for Social Welfare in Polkowice}

The local government is a local or regional self-governing community. These units are selfcontained and autonomous in functioning in the sphere of public activities of local importance. Units conduct their business in their own name and to their own responsibility. This means that each of them, within its field of competence, itself defines all the aims, possible ways of achieving them and is responsible for the execution of these tasks.

Polkowice Municipality is located in northern part of the Lower Silesia Region, in an industrial area, called "The Copper Basin", which is also the economic engine of Lower Silesia.

The main decision-making body in the commune is the Mayor of the municipality of Polkowice Municipality. Under Polish law, the Mayor is the executive body of the municipality.

Units subordinate to the Municipality Office in Polkowice include:

- Municipal Police,

- Centre for Social Welfare,

- Primary schools,

- Secondary schools,

- Nurseries,

- Municipal Public Library,

- The company Urban Economy,

- Village Cultural Centre in Sobin.

Auxiliary units in the municipality include:

- Council housing estates, and,

- Villages. 
Exemplary main tasks of the Centre for Social Welfare are following:

- the study and the realization of the commune strategy of solving social issues

- drafting balance of needs of the commune in the welfare

- giving shelter, providing the meal and essential clothes for persons deprived of it

- admitting and paying periodic benefits

- admitting and paying designated benefits

- admitting and paying designated benefits for the coverage of expenditure incurred as a result of the fortuitous events

- admitting and paying designated benefits for the coverage of expenditure to health benefits to homeless persons and other persons who have no income and the possibility of obtaining of benefits pursuant to provisions on universal insurance

- granting designated benefits in the form of ticket provided credit

- paying contribution to pension and social security insurance for the person which will give up employing in relation to the need to exercise the direct, personal care above for a long time or with seriously ill family members

- social work

- organizing and providing care services in the domicile

- leading and securing places at social and behavioral institutions

- feeding children

- causing the funeral for homeless persons.

The Centre for Social Welfare realizes also tasks coming from the government administration:

- admitting and paying fixed benefits

- paying contribution to the health insurance

- organizing and providing specialist care services in the domicile for persons with psychic disturbances

- admitting and paying designated benefits for the coverage of expenditure connected with natural or ecological disasters

- execution of tasks of the assistance resulting from government social programs.

\section{Role of BI in Local Government Units}

This paper sets out to explore and explain if and why BI solutions are used or not used by decision makers. As mentioned above, the analysis is conducted on a case study. At this stage, the key question is: Why do public sector or government agencies require $\mathrm{BI}$ ?

According to MAIA Intelligence Company (http://maia-intelligence.com), it is required for:

- measurement, management and reporting on performance

- logistics

- formation of policy

- planning and budgeting

- statutory reporting and best value

- aiding in joined government to improve service

- public information

- inter-agency liaison (single view of citizen)

- exploration of hidden relationships in data

- disease surveillance and public health

- identifying tax fraud and money laundering 
- homeland security

- crime prevention

Enterprises obtain and collect huge amounts of information. Finding the information needed to manage the enterprise takes time and is difficult without support of a computer system. The ability to foresee changes that occur in an enterprise business environment, or customer requirements, as well as an ability to react quickly to such changes are necessary for an enterprise to survive and function well.

Business intelligence derives from a group of IT tools defined as BI. H. Dresner, from Gartner Group, was one of the first to introduce the BI concept in 1989. He defined it as a set of conceptions and methods that enhance the process of decisions making by using fact-based support systems.

Business Intelligence can be understood as a process of obtaining important and high-quality information on various subjects that will help a person or group of people in analyzing information, concluding or making assumptions. From the perspective of information systems, BI is understood as a group of systems that provide their users, by means of OLAP technology and data analysis, with answers to important business queries and enables identification of significant trends or patterns. However, the easiest way to describe it is to say that BI is an information technology used to process big amounts of data into information, and that information into knowledge. It is addressed to decision-makers on various levels of management, mostly strategic and tactical management, as well as to marketing and personnel analysts and others.

$\mathrm{BI}$ can be seen as a managerial strategy used to create a more structured and effective approach to decision making. G. Nelson said "the cornerstone of this 'fact-based' decisioning framework is technology that allows us to access, analyze and present information" (Nelson, 2010). BI includes elements of reporting, querying, OLAP, dashboards, scorecards and analytics. Facts can be analyzed but nothing can be said about the processes that led to the facts.

The BI system is aimed at promoting the economic processes taking place in a public entity. However, the same data storage, although necessary in everyday work, is a value in itself. One of the factors enabling significant competitive advantage is information that can be obtained with the data stored in the systems functioning throughout the institution and using this information to make tactical and strategic decisions. It can be said the information in the reports is generated from the systems described above.

\section{BI Solutions Dedicated to the Local Government Unit}

Organization management systems are unsuitable for this type of analysis (designed for efficient processing of small portions of data, e.g. a recording contract, an invoice, a price list, but not for cross-cutting analysis of large chunks of data). Typically, organization management systems maintain only current information on most objects (e.g. about citizens) without storing the history of changes to its data. This can lead to many misunderstandings (e.g. in a situation where a citizen will change their name, address or marital status). Even worse, not only a single system is dealt with, but also multiple systems used by different units in the institution, which may lead to a slightly different understanding of certain concepts by different groups of people. Moreover, a particular public service can be seen as something different in one department and something completely different in another. It is often necessary to compare current rates with those from previous years.

BI technology uses different IT resources, mainly databases (current and archival) available in an enterprise. A place of BI among IT systems that support management can be seen as in Fig. 1. 


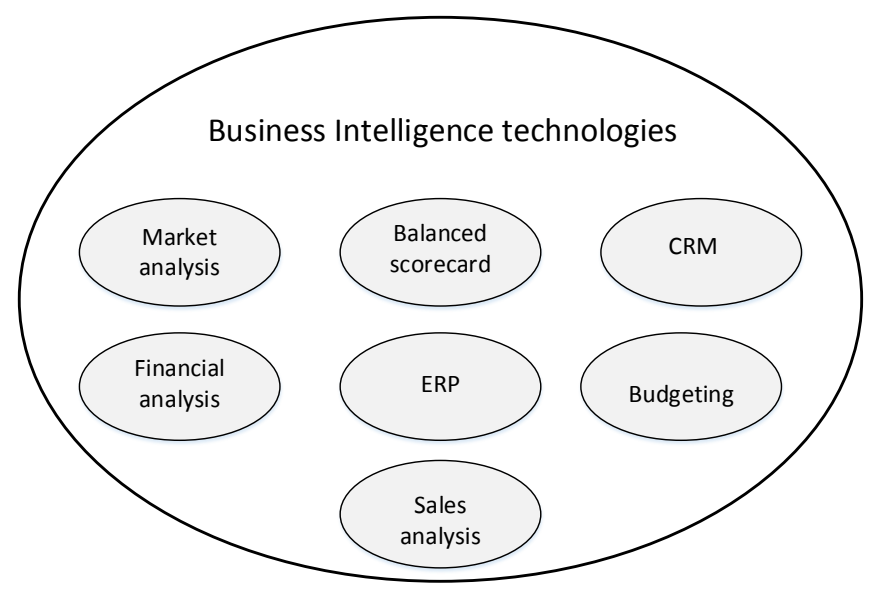

Figure 1. BI technologies among management information systems Source: own elaboration

As shown, BI is the center of attention within all information solutions in an organization and can be treated as a "binder" as well as a "facilitator" of the enterprise's improvement.

There are some requirements put towards BI:

- integration of data from heterogeneous sources into one coherent data store

- delivery of interactive possibilities for data manipulation

- different ways of data presentation (graphics, tables, standard and ad hoc reports, etc.)

- simplicity of use

- BI should guarantee an appropriate level of security and limit access to data

The model of BI is shown in Fig. 2, where under the term "system modules", such modules are understood as financial and accounting, CRM (Customer Relationship Management), ERP (Enterprise Resource Planning), human resources, etc.

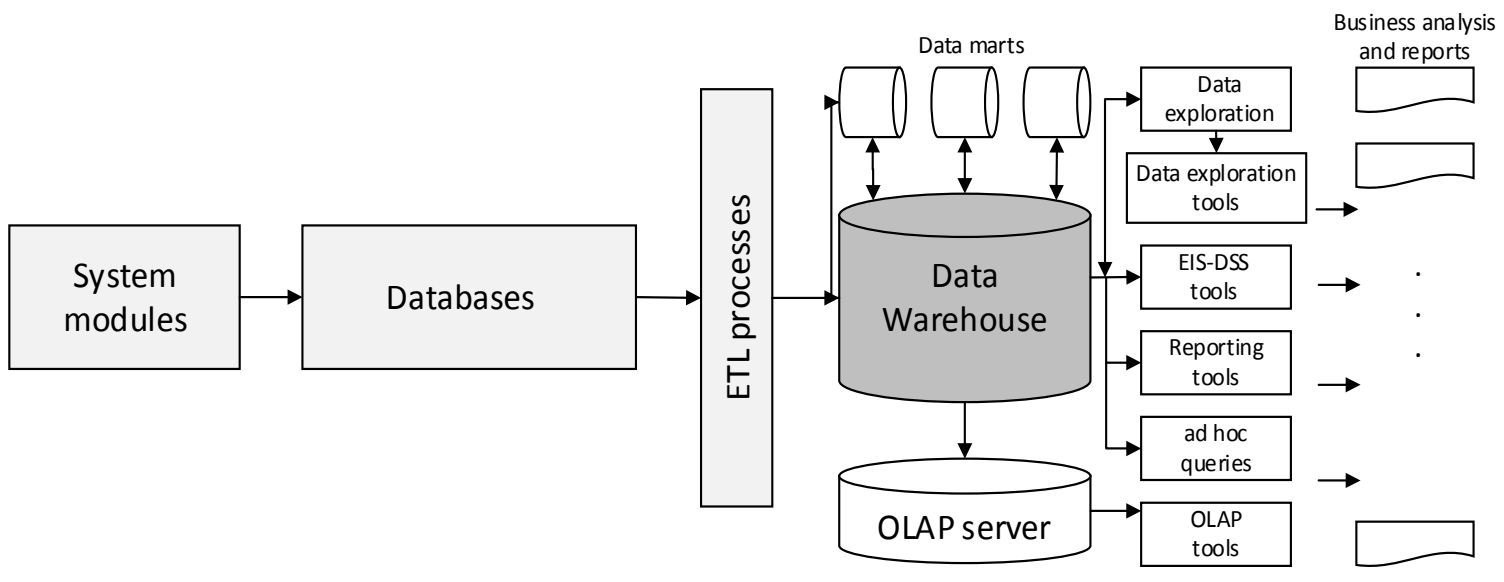

Figure 2. The BI model

Source: based on Computerworld, 2003

The BI process starts with a business enquiry, which comes from a decision-maker, and finishes when a suitable, comfortable, and understandable answer (e.g. tables, charts) is delivered (Nycz, 2007). 
The BI technology can be treated as a technology of information collecting and delivering. A data warehouse (DW) is the basic element of any BI system. A data warehouse integrates data from various source systems. It enables gathering and processing of data within the required process, for example multidimensional, analyses or data mining. Next, the results are visualized (Fig. 3).

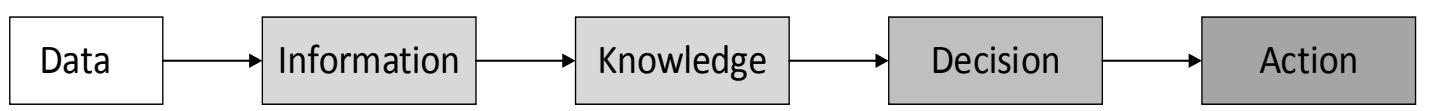

Figure 3. Realization of the BI process

Source: Nycz, 2007

The analysis of data makes it possible to better understand phenomena that are of interest in a given enterprise. It also enables users to seek out and assess relations among the investigated phenomena, to identify critical factors affecting these phenomena, to assess particular effects of the undertaken activity, and to assess the diversity of the obtained effects for an individual group of consumers and to search for the reasons of these diversity.

The in-depth analysis results can increase the effectiveness of undertaken activities, improve effects of the projects in progress and allow planning these activities and projects in a more effective way. The analysis of historical data collected for reporting purposes can be the basis for better predictions for the future.

A data warehouse is a core element of any business intelligence system, due to the fact it integrates data within the whole enterprise (Immon, 2002). Integrated data are processed by means of analytical applications that support the decision making process (Todman, 2011). A multidimensional model of data comprises two categories of data: facts and dimensions. Facts are information being analyzed and are characterized by measures. Dimensions decide the context of analysis and consist of levels creating hierarchies. Connected relations of facts and dimensions create a data model. There are three main data models in DW: a star, a snowflake and a constellation of facts (Kimball, Ross, 2013). A star schema is one of the most often implemented within a DW. In a DW, only facts are collected. No information is collected regarding relations between facts or about processes within which these facts appeared. Data analyses can provide answers to such business questions as "How did the sale of our products look in the 2007-2009 period?" The answers are always numbers, and the measures are, by definition, of a numeric type (Fig. 4).

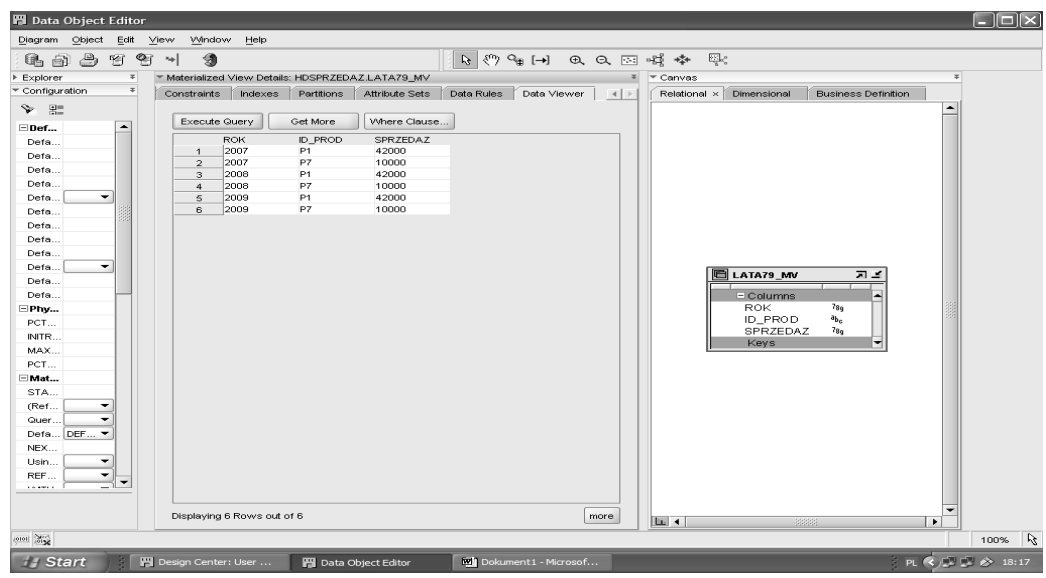

Figure 4. The answer to a simple business query

Source: own elaboration

Alternatively, for each manager, information of a qualitative nature is also interesting. For example: who among the employees was responsible for the sale, what are the employee's competen- 
cies, how long were negotiations, what problems occurred, etc. The traditional DW is unable to generate the answers due to the fact it has no ability to analyze processes within the enterprise.

Knowledge collected in databases of local government units is a valuable resource, which in order to be useful, must be extracted. The databases currently used were created for completely different purposes than collecting knowledge. Knowledge can be also in a tacit form (from personal sources). In the local government units, employees contact one another in various ways: in person, by phone, fax, e-mail. It is essential to know where to look for the knowledge needed, who possesses it, in which documents, files, legal acts or monographs it can be found. Moreover, time spent on searching the needed knowledge is a crucial factor in a given decisive situation.

The objectives of the creation of the business intelligence system in the Polkowice Commune can be outlined as follows:

- data consolidation, finance, projects undertaken by the local government, etc.

- online access to pre-defined reports

- ability to plan, simulate and forecast

- instant access to strategic data and business analysis

Typical applications of this group of BI:

- strategic planning

- analysis of CRM

- controlling and management accounting

- profitability of products, services, etc.

- analysis of internal processes

The requirements of the BI system can be formulated as follows:

- integrating data from multiple sources into a single, basic and consistent data store

- providing truly interactive data manipulation capabilities

- offering multiple ways of presenting data (graphics, tables, standard and obtained an adhoc statement)

- allowing the user to refill the application elements that are "extracts" of their own intelligence

- simple and intuitive use

- ensuring the functionality of the protective security and limiting access to data

BI provides complete information (depending on the demand), which is then used in the decision process, and this in turn, is directly related to the tasks of local government units (MSWIA, 2014). They can be divided into four such groups (Infor, 2014):

- tasks of the technical infrastructure of the municipality (roads, bridges, streets, sewer, water, cleaning, garbage dumps, etc.)

- tasks of social infrastructure (health, culture, education, physical education, social assistance)

- tasks in the field of public order and safety (traffic, public order, fire protection, safety, sanitation).

- tasks in the field of spatial order and ecology (spatial planning, management areas, environmental protection)

As previously mentioned, the DW is a core element of the BI system. The BI system can be designed on the level of the commune office, which will integrate data coming from the budget 
units, non-budget within budget units and budget institutions into the DW, but not all the data these units work on; only those necessary on the commune office level, where they will be processed to support decision-making processes on that level. In an accompanying paper, selected information systems used in local units are briefly presented. In most cases they are heterogenic. If analyses are to be carried out on these data and conclusions drawn, they have to be integrated in the warehoused, allowing data models to be created according to the business questions coming from the managers of the commune office. Some will be of the star model and, some of the snowflake. Finally, the constellation of facts should be obtained. When the necessary source data (from the local unit databases, through the ETL process) come to dimensions and facts, the DW may be described as ready for work. This means that processes of multidimensional, often very complex analyses can be carried out by means of dedicated software to particular requirements, for example, financial (see above). The results of analyses would be presented in a form required by the particular manager: in the shape of tables, graphs, in printed form or displayed on the managerial cockpit. To compare results, it is possible for the manager to dynamically change the scope of the analyzed data, the analyzed period of time, etc.

The proper implementation of BI technology is expected to successfully support local authorities in decision-making processes.

\section{Conclusions}

The obligation for the proper functioning of society is to create a particular social order and allowing its smooth functioning. Effective management of public institutions is currently one of the biggest challenges modern economies face. This paper presented how implementation of new IT solutions, such as BI, can support a local authority in decision-making processes to fulfill the expectations of the Polkowice inhabitants.

In comparison with previous literature, our analysis based on the case study has provided an analysis of the problem of whether and why managers use or do not use BI solutions for improving business processes. BI solutions are not commonly accessible in local government units when they should be made available to all departments that take part in the managing process.

While the cause of the problem can be determined, remedial measures are not clear. In theory, the software should improve the quality of software for the management of social centers to allow flexibility desired by the users. In addition, it is expected that the Ministry of Social Policy will recommend some BI solutions. Typically, users of construction management accounting reports conduct analysis in an ad-hoc manner.

From an academic perspective, this study contributes to a theoretical account of solution weakness in management control functions. Assumptions that BI solutions are appropriate not only for business but for non-profit institutions were earlier confirmed.

From the perspective of a practitioner, this study informs managers to set realistic expectations of BI solutions to successfully develop in reality. Moreover, managers can predict and plan investments, including training, recruitment policy, and software and hardware investments.

The study shows that a growing need to use methods and tools for the analysis of business processes in information systems is of great importance in the departments responsible for making decisions (management, accounting, human resources, payroll). 


\section{References}

Baxter, P., \& Jack, S. (2008). Qualitative case study methodology: Study design and implementation for novice researchers. The Qualitative Report, 13(4), 544-559. Retrieved from http://www.nova.edu/ssss/QR/QR13-4/baxter.pdf

The BI model. (2003). Computerworld.

Business Intelligence for Public Sector Government. (2014). MAIA Intelligence. Retrieved from http://www.maia-intelligence.com/pdf/1KEY-Agile-BI-Suite-for-Public-Sector-Government.pdf

GUS: Strategy for Sustainable Development in Poland. (2011). Retrieved from http://stat.gov.pl/cps/rde/xbcr/gus/as_Sustainable_Development_Indicators_for_Poland.pdf

Himanshu Tiwari. (2014). Data mining, warehousing and OLAP technology. Discovery, 24(83).

Infor. (2014) Retrieved from http://www.infor.pl/prawo/encyklopedia-prawa/j/273389,Jednostkasamorzadu-terytorialnego.html

Inmon, W.H. (2002). Building the Data Warehouse (3rd ed.). New York, NY: Wiley Computer Publishing.

Kaminska, T. (2010). The information society in Poland - The individuals' approach. International Journal of Emerging and Transition Economies, 3(2), 269-284.

Kimbal R., \& Ross M. (2013). The data warehouse toolkit: The definitive guide to dimensional modeling (3rd ed.). Wiley \& Sons.

MSWIA. (2014). Retrieved from http://www.mswia.gov.pl/portal/pl/321/4328/Administracja publiczna.html

Nelson, G., (2010). Business Intelligence 2.0: Are we there yet, SAS Global Forum.

Nycz M. (2007). Pozyskiwanie wiedzy menedżerskiej. Podejście technologiczne, Wyd. AE, Wrocław.

Nycz M., \& Pólkowski Z. (2014). The ERP System as a Basic System for Business Analyses. Bucarest.

Olawale, A. (2012). The role of business intelligence in government: A case study of a Swedish municipality contact center. Master's Thesis in Informatics, Trollhattan.

Olszak, M. C., \& Ziemba E. (2010). Knowledge management curriculum development: Linking with real business needs. Issues in Informing Science and Information Technology, 7, 235-248. Retrieved from http://iisit.org/Vol7/IISITv7p235-248Olszak830.pdf

Sauer A., (2013). The system of the local self-governments in Poland. Association for International Affairs. Sustainable Development Indicators for Poland. (2011). Central Statistical Office, Katowice.

Todman, C., (2011). Designing a data warehouse. Prentice Hall

Yin, K. R. (2009). Case study research. Thousand Oaks.

\section{Biography}

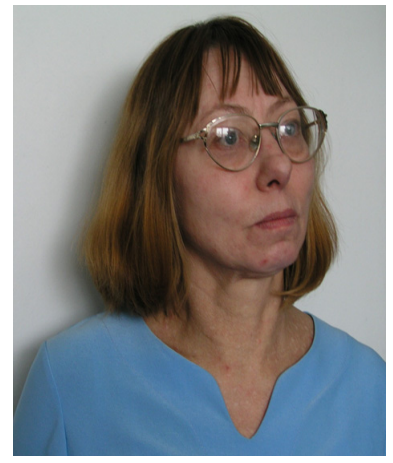

Professor Malgorzata Nycz, PhD, is an associate professor at the department of Artificial Intelligence Systems of Wrocław University. She has authored many publications, mainly oriented on intelligent system topics, business intelligence, data warehouses and distance learning issues. Her current research is in intelligent systems with a focus on knowledge discovery from databases and modern education including e- learning processes. Prof. Nycz runs classes in subjects such as computer science, databases, basic artificial intelligence, data warehousing, business intelligence management and business intelligence across an enterprise. 


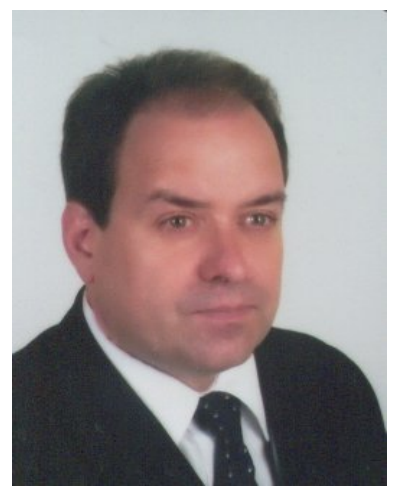

Dr. Zdzisław Pólkowski, PhD, is an assistant professor at the Department of Technology at The Lower Silesian University of Entrepreneurship and Technology (DWSPiT) in Polkowice, Poland. He runs classes within the fields of business informatics, e-administration and IT. He conducts research in such business informatics as e-business, ecommerce, IT systems in business and ERP systems. Dr. Pólkowski maintains contacts with numerous academics in Poland and abroad. Moreover, he is the owner of a small company, where he tries and tests new ideas in practice. In Polkowice, he has carried out many IT projects, especially in schools, small companies and government institutions. Contact with other small companies allows him to define the upto-date state of using IT tools in business. Website:

www.studenci.polkowski.com.pl. 